\title{
An Investigation into Power from Pitch-Surge Point-Absorber Wave Energy Converters
}

\author{
Robert V. Chaplin and George A. Aggidis \\ Lancaster University, Engineering Department, Renewable Energy Group, Faculty of Science and Technology \\ Lancaster, LA1 4YR, England, r.chaplin@1ancaster.ac.uk
}

\begin{abstract}
There is a worldwide opportunity for clean renewable power. The results from the UK Government's "Marine Energy Challenge" showed that marine energy has the potential to become competitive with other forms of energy. The key to success in this lies in a low lifetime-cost of power as delivered to the user. Pitch-surge pointabsorber WECs have the potential to do this with average annual powers of around $2 \mathrm{MW}$ in North Atlantic conditions from relatively small devices that would be economically competitive with other technologies and would be relatively easy to install and maintain. The paper examines the factors governing the performance of such devices and outlines their underlying theory Preliminary laboratory test results from a 1/100 scale pilot design are presented. It is hoped that more extensive development work will follow these promising early results. Engineering designs for devices based on these findings are outlined.
\end{abstract}

Index Terms - Extreme-wave, Pitching-surge, Pointabsorber, Wave Energy Converter

\section{INTRODUCTION}

For a wave energy converter (WEC) to be economic it must be small but powerful: it must have a high output per expensive ton [1]. Successive devices devised and investigated at Lancaster University and elsewhere have had this clear aim. [1,2,4,5,6,20] The Cost term in assessing any of these concepts must be the lifetime cost per unit of energy delivered ( e.g. in $\mathrm{p} / \mathrm{kWh}$ ) and this implies an imperative for survival in the worst storms and a minimum of on-site maintenance.

Pitching-surge Collectors hinged at or near the seabed were proposed in 1998 [6] and have since been developed at QUB, Lancaster and elsewhere for near-shore conditions $[5,7]$.

It has been widely believed in the wave power community that, to be economic, devices must be offshore in deep water where average energy levels are highest $[1,10]$. However, much of this energy comes in storms in amounts that no device could capture. It seems now that the converse may be true: that the steadily decreasing water depths (e.g. West of the Hebrides) will act to protect near-shore devices from extreme forces and, overall, make them a rational economic choice [8]

Point absorbers (PA) first described and investigated by Budal \& Falnes [9] are likely to have the least cost but heaving types proved difficult to engineer and their likely survival in storms is questionable. Evans [3] showed that a PA moving in surge has an ideal power twice that of a heaving PA and that :-

$$
\begin{aligned}
& \text { PA capture width (Heave) }=\lambda / 2 \pi \\
& \text { PA " " } \quad(\text { Surge })=\lambda / \pi
\end{aligned}
$$

A means of calculating ideal power and amplitude of a particular PA collector is given by Evans [3,11] and investigated by Folley [ 4 ] :-

$$
\begin{aligned}
& \mathrm{P}_{\mathrm{o}}=\mathrm{Q}^{2} / 8 \mathrm{~B} \\
& \mathrm{x}_{\mathrm{o}}=\mathrm{Q} / 2 \mathrm{~B} \omega
\end{aligned}
$$

where $\mathrm{Q}=$ Total wave force on the collector, $\mathrm{N}$ $\mathrm{B}=$ Radiation coeff of the collector, $\mathrm{Ns} / \mathrm{m}$

$\omega=$ Wave frequency, $\mathrm{rad} / \mathrm{s}$

For example, a typical (model) collector body of area $20 \times 20 \mathrm{~cm}$ and $4 \mathrm{~cm}$ thick with fully radiused edges in waves with $1.2 \mathrm{~cm}$ amplitude would have $\mathrm{Q}=2.8 \mathrm{~N}, \mathrm{~B}=$ $4 \mathrm{Ns} / \mathrm{m}$ and $\mathrm{x}_{\mathrm{o}}=0.054 \mathrm{~m}$ based on values obtained using WAMIT [12]. At full scale $\mathrm{x}_{\mathrm{o}}$ scales to $5.4 \mathrm{~m}$ so the plate-like collector's velocity would peak at $3 \mathrm{~m} / \mathrm{s}$ normal to its face. Clearly this would result in large drag forces acting on the collector and a reduction in the net (output) power.

Preliminary experiments, with a range of collector shapes that were guided to translate horizontally in the surge direction and made resonant with the waves using springs, showed that the above is essentially true and collector amplitudes of up to $6 \mathrm{x}$ wave amplitude were observed [13]. It was noted that, when power was being extracted at these large amplitudes, the wave amplitude ahead of the collect was locally amplified and was much greater that in the lee of the collector where the water surface remained almost flat. This served to demonstrate the physical reality of the PA effect in surge and to validate the equations above. Questions remained about the nature of the drag forces, possibly, in part, answered by Ridjanovic [14] but one thing was clear, the resonant mass would be very large.

Added Mass, $\mathrm{M}_{\mathrm{a}}=6.05 \mathrm{~kg}$ for $20 \times 20 \times 4 \mathrm{~cm}$ plate mentioned above moving at $6 \mathrm{rad} / \mathrm{s}$

Body Mass, $\mathrm{M}_{\mathrm{b}}=0.32 \mathrm{~kg}$, assuming "ship-like" density of $200 \mathrm{~kg} / \mathrm{m}^{3}$

$$
\mathrm{M}=\mathrm{M}_{\mathrm{a}}+\mathrm{M}_{\mathrm{b}}=6.37 \quad \mathrm{~kg} \text { at } 1 / 100 \text { scale }
$$




\section{Equivalent to $\mathrm{M}=6370 \mathrm{t}$ at full scale}

For such a mass to be resonant in surge would require a spring that would be economically infeasible.

However, fitting the collector body to the upper end of a lever whose lower end is pivoted at or near the seabed, such that the body moves in surge in a shallow arc, closely approximates the spring-centred mechanism investigated above but is now in the form of a practical and robust machine (Fig.1).

In summary:-

\begin{tabular}{|c|c|c|c|c|}
\hline PA Type & $\begin{array}{c}\text { Ideal } \\
\text { Capture } \\
\text { Width }\end{array}$ & $\begin{array}{c}\text { Naturally } \\
\text { Resonant? }\end{array}$ & Practical? & $\begin{array}{c}\text { Storm } \\
\text { Survival }\end{array}$ \\
\hline Heave & $\lambda / 2 \pi$ & Yes & Difficult & Difficult \\
Surge & $\lambda / \pi$ & No & No & NA \\
$\begin{array}{c}\text { Pitching- } \\
\text { Surge }\end{array}$ & $\lambda / \pi$ & Yes & Yes & Yes \\
\hline
\end{tabular}

At QUB [15] the Oyster device being developed for depths $10-15 \mathrm{~m}$ is already at an advanced stage of development. This paper gives preliminary results for "WRASPA", a WEC intended for deeper waters 20-50 m found further offshore.

Although the devices are similar in operation the hydrodynamic conditions they will face in reality are likely to be very different in terms e.g. of breaking wave forces and shoaling effects.
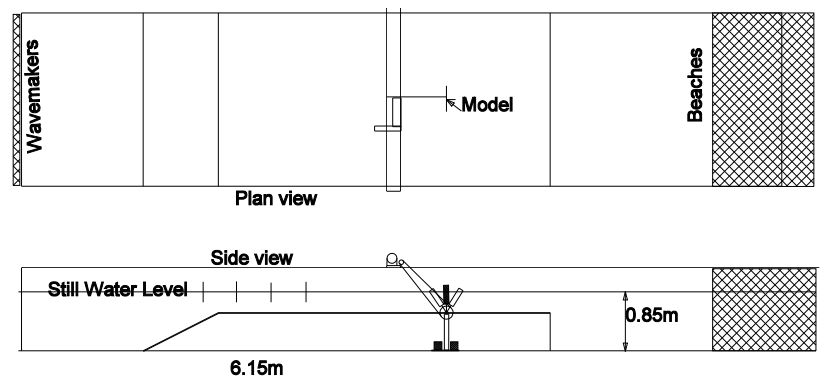

Fig. 1. Model and tank-general arrangement

\section{THE CONCEPT DEVICE, WRASPA*}

(* Wave-driven $\underline{\text { Resonant }}$ Arcuate-action $\underline{\text { Surging }}$ Point Absorber)

Until laboratory tests and digital modelling have shown the best form of the device [16] we are uncertain as to its engineering details. Currently we envisage a self-contained machine weighing about $500 \mathrm{t}$ without ballast and over $1000 \mathrm{t}$ when ballasted and on-site, see Fig 2. The collector and arm would be driven to and fro by wave forces. The arm would drive 3 or more hydraulic rams, attached to the base unit. Housed in the base unit a power conversion system containing an energy store would adapt to differing wave forces and deliver steady power to an on-board electrical generator.

Deployment and recovery would be by crane from a suitable service vessel with the base unit being inserted into the top of a tubular seabed pile. The whole device would be ballasted at or near the pivot to float at the depth shown and would be actively controlled to face the prevailing energy direction at all times.

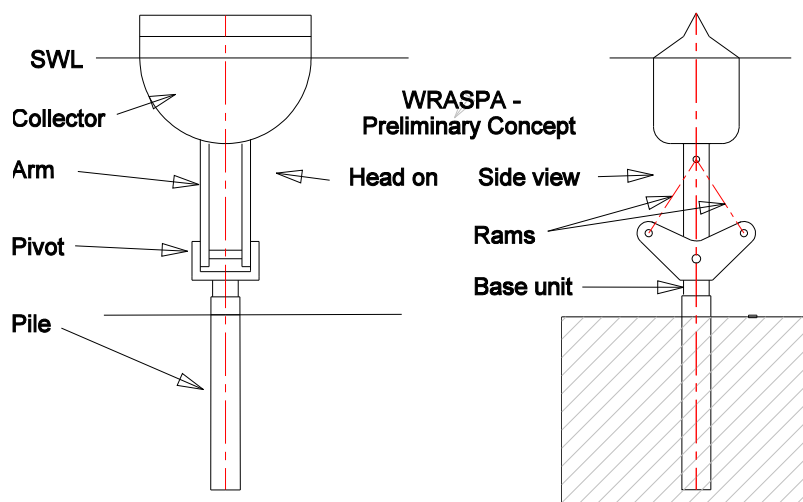

Fig.2 Initial concept

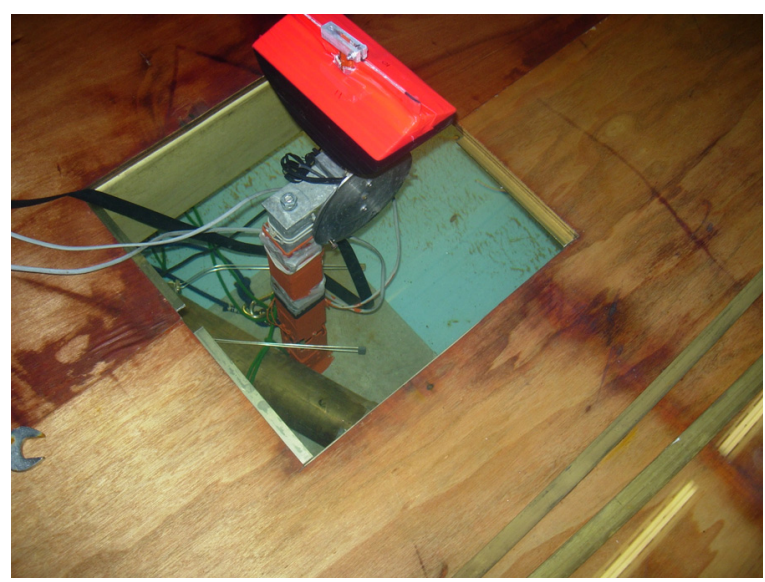

Fig. 3. Apparatus in tank - covers removed from seabed hatch to show pile.

\section{APPARATUS}

\section{A. The Tank}

Fig 3 (above) is a diagram of the apparatus used. The "raised seabed" was formed from a set of 4 large tables and a ramp that forced waves generated by the ED wavemakers [17] into water some $65 \%$ shallower and the $3 \mathrm{~m}$ length of shallower ( $30 \mathrm{~cm}$ deep) water allowed the wave to stabilise before reaching the model.

In long-period, long-crested, non-breaking waves the amplitudes decreased as they passed down the tank as shown (Fig.4). However, the same fig also shows that shorter period waves are less affected by shallow water and appear to lose very little energy. The shape, of longer period waves in particular, became more trochoidal as they moved down the tank e.g. see Fig 5.

There was concern that the standing wave ratio might be adversely affected by the ramp and tables but Fig 6 shows, in the frequency range of interest, a SWR less than $15 \%$ (implying reflected energy $<2.5 \%$ ) i.e. that the beach, based on proven ideas from Edinburgh University [18] works well and for tests at $1 / 100$ scale the shallowing of the tank presents no problems.

Breaking waves, however, are a problem in near-shore sites and have proved fatal for at least one pilot scale WEC [19]. At larger wavemaker amplitudes in the now 
shallow tank it was easy to exceed the steepness limit and produce breakers - see Fig 15. Again the $3 \mathrm{~m}$ "lead-in" to the model served to give reasonably realistic "continental-shelf" test conditions in extreme seas.

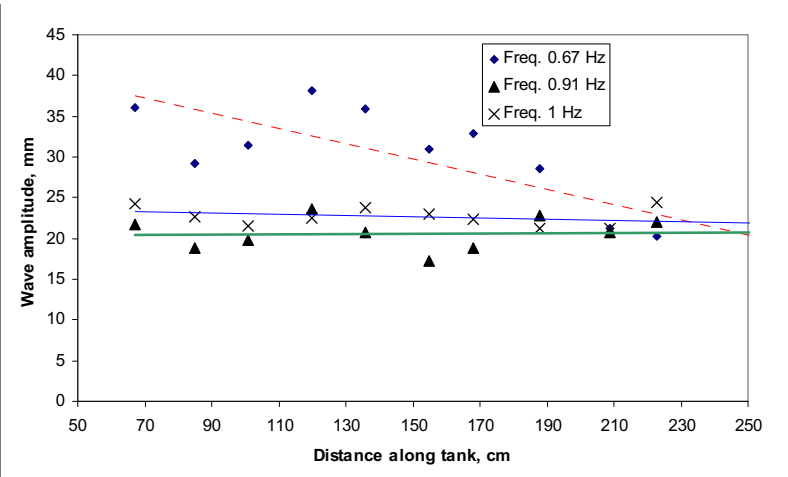

Fig. 4. Wave attenuation $30 \mathrm{~cm}$ water depth

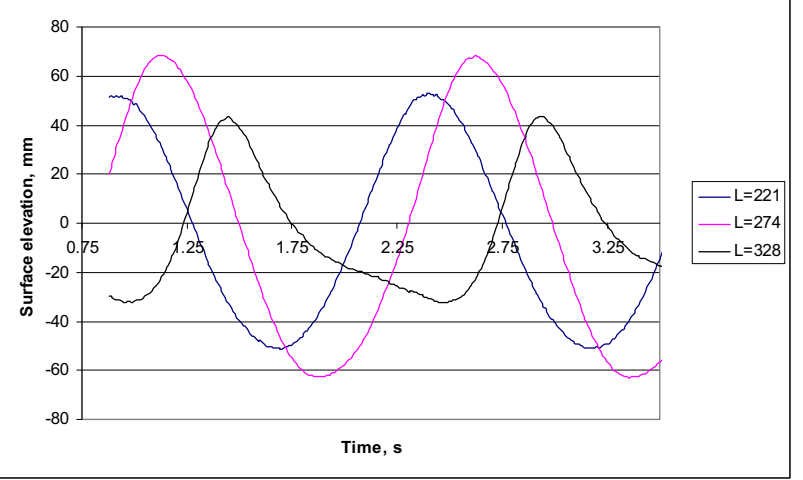

Fig. 5. Wave shapes in $30 \mathrm{~cm}$ water depth $-0.67 \mathrm{~Hz}$

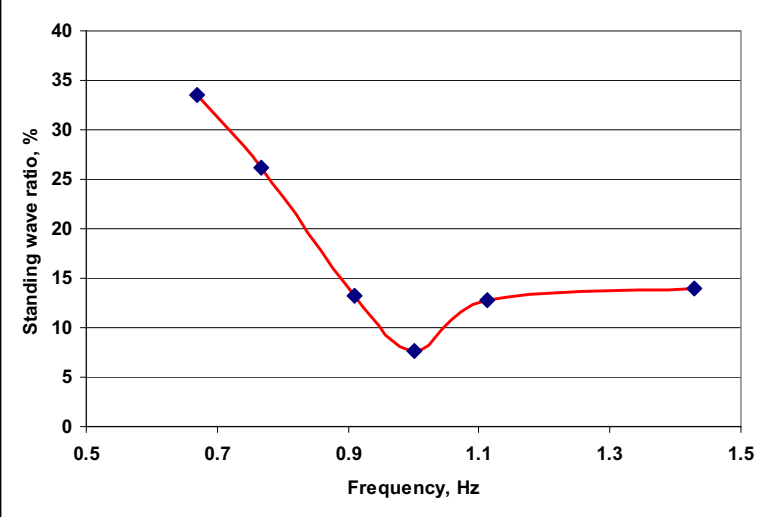

Fig. 6. Standing wave ratio vs wave frequency - water depth $30 \mathrm{~cm}$

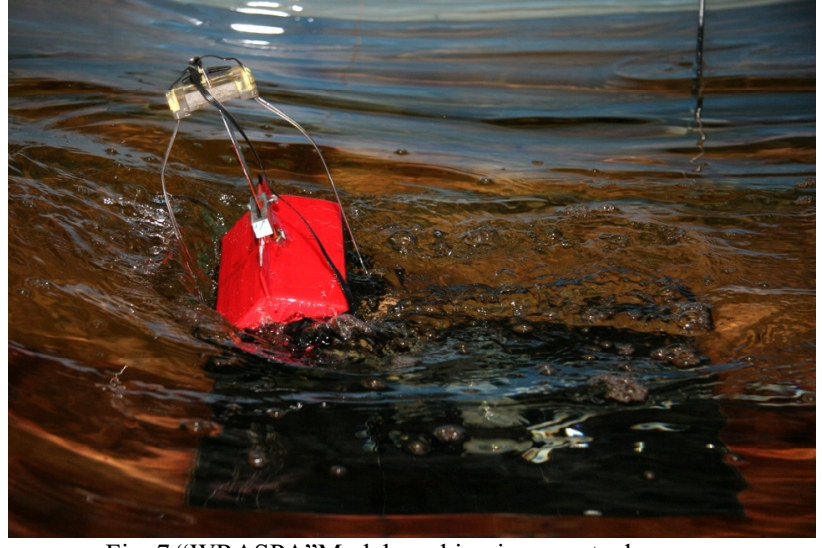

Fig. 7 "WRASPA"Model working in wave tank

\section{B. The Model}

The collector, $10 \mathrm{~cm}$ thick $\mathrm{x} 10 \mathrm{~cm}$ radius, was immersed to a depth of $10 \mathrm{~cm}$, with $5 \mathrm{~cm}$ freeboard and weighed $140 \mathrm{gm}$, dry, giving it a density of $90 \mathrm{~kg} / \mathrm{m}^{3}$. Its position on the arm is adjustable but for these tests the waterline was set at $250 \mathrm{~mm}$ from the pivot. The arm was strain-gauged at 55 and $111 \mathrm{~mm}$ from the pivot and was calibrated with known weights to give :-

$\mathrm{M}_{1}=\mathrm{k}_{1} \mathrm{~V}_{1}$ and $\mathrm{M}_{2}=\mathrm{k}_{2} \mathrm{~V}_{2}$

Where:- $\mathrm{V}_{\mathrm{n}}=$ logged volts

$\mathrm{M}_{\mathrm{n}}=$ moment $\mathrm{Nm}$ (measured at the s.gauge)

$\mathrm{k}_{\mathrm{n}}=$ factor $\mathrm{Nmm} / \mathrm{V}$

from these it was possible to calculate :-

$\mathrm{F}=\left(\mathrm{M}_{1}-\mathrm{M}_{2}\right) / 0.056$

$\mathrm{Z}=\left(\mathrm{M}_{1}+.055 \mathrm{~F}\right) / \mathrm{F}$

Where: $\mathrm{F}=$ total force acting, $\mathrm{N}$ and $\mathrm{Z}=$ effective distance of $\mathrm{F}$ from pivot, $\mathrm{mm}$

The motion of the arm was geared up by 4.374 and measured using a 10-turn precision potentiometer.

When measuring power the geared-up shaft was acted on by 3 electrically operated clutches each connected to a small band-brake. These were loaded with hanging weights of (say) 100, 200 and 400 grammes such that switching the brakes on in different combinations gave 8 levels of torque. (The shaft could also be connected by another clutch to a pancake motor but this was not used in these experiments).

The arm was carried on a shaft running in small stainless steel ball races mounted in the top of an adjustable height "pile" that stood on the tank floor, held down by large brass weights. A strain-gauge bridge at the lower end of the pile measured horizontal forces at the pivot. Twelve wave gauges were arranged to measure the oncoming wave and local waves ahead, astern and abeam of the model and in all, 16 "channels" of data were recorded using a Labview $($ program. 


\section{METHOD}

\section{A. Resonance sweep}

With all brakes switched off the only applied damping was the small amount of friction in the bearings in the pivot and driven shafts. In this state sine waves of steadily increasing frequency were passed down the tank and an "envelope" of collector motion amplitudes was obtained.

\section{B. Power}

Steady-state waves at about the resonant frequency were run past the model while brake loads were increased from zero to a maximum in load steps lasting for $30 \mathrm{sec}$.

\section{Mixed Seas}

Although fixed-load braking is not the intended final control method a series of initial tests with an "intermediate" load were carried out in Bretchsneider seas [17] of differing energy levels and with time periods close to the resonant frequency of the model.

\section{Extreme wave loading}

For these trials the drive cord was removed so the arm was unimpeded in its motion. The motions recorded were obtained from video recordings by comparing observed motions with fixed markers ahead and astern of the model.

\section{RESUlts}

\section{A. Resonance}

Results of the resonance sweep are seen in Fig. 8 and show that the frequency response is fairly flat. If the model's resonant frequency was at the scaled centre of an annual spectrum of Atlantic waves the diminution in amplitude at each end of the spectrum $(\mathrm{T}=8 \mathrm{~s}$ to $\mathrm{T}=12 \mathrm{~s}$ nominally) might be as little as $30 \%$.

\section{B. Regular-wave power}

From the above sweep test a peak frequency of $0.805 \mathrm{~Hz}$ was chosen and used in all power tests. For each wave-size brake loads were varied in steps and Fig. 9 shows examples of work loops each recorded at the midpoint of a 30second load-step. The loops are drawn clockwise so at times when motion is +ve, force is +ve and v.v. Thus the area inside the loop indicates work done in 1 cycle.

$$
\begin{array}{ll}
\mathrm{A}=\mathrm{T} \theta & \mathrm{A}=\text { area, } \mathrm{J} \\
\mathrm{T}=\mathrm{p}-\mathrm{p} \text { torque at pivot, } \mathrm{Nm} \\
\theta=\mathrm{p}-\mathrm{p} \text { motion, rad }
\end{array}
$$

Power then is $\mathrm{P}=\mathrm{A} \omega, \mathrm{W}$

Where $\omega=$ frequency $\mathrm{Hz}$.

By plotting torque vs amplitude, see e.g. the lowest curve in Fig.10, it can be seen they are in an inverse, probably linear, relationship and that the $\mathrm{x}=0$ and $\mathrm{x}$ max intercepts respectively represent the "locked" and "free" limits in each condition.
It follows that the power curve is parabolic with a peak at an amplitude of $x_{\max } / 2$ and zeroes at 0,0 and $x_{\max }, 0$, see also Fig.10. The same fig. also shows the derived parabola of Capture Width (captured power, $\mathrm{kW}$ /incident wave power, $\mathrm{kW} / \mathrm{m}$ )

Taking peak values from these curves for each of the regular wave sizes studied gives the variation of device power vs incident wave power plotted in Fig. 11. The best-fit line appears to intercept the y axis at a positive value suggesting that collector "efficiency" improves in smaller waves. Thus, capture widths $(\mathrm{CW})$ plotted in the same figure show a marked increase at smaller amplitudes to possibly $8 \mathrm{~m}$ or more in waves of less than $100 \mathrm{kw} / \mathrm{m}$

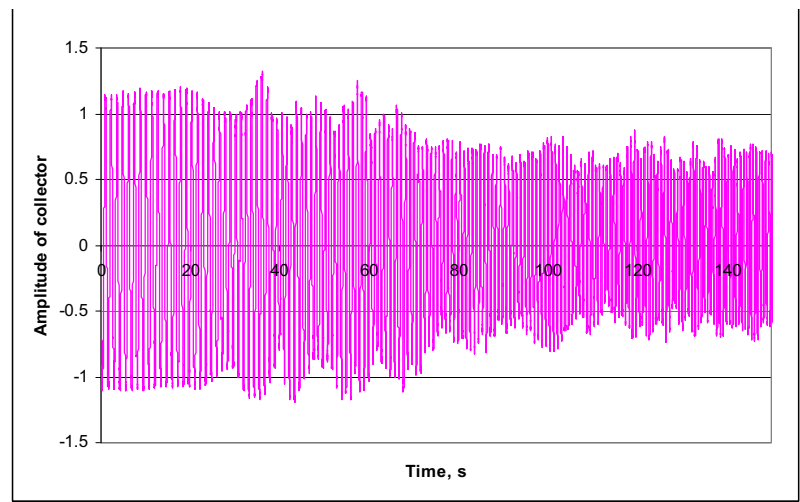

Fig. 8. Frequency sweep from $0.67-1.43 \mathrm{~Hz}$

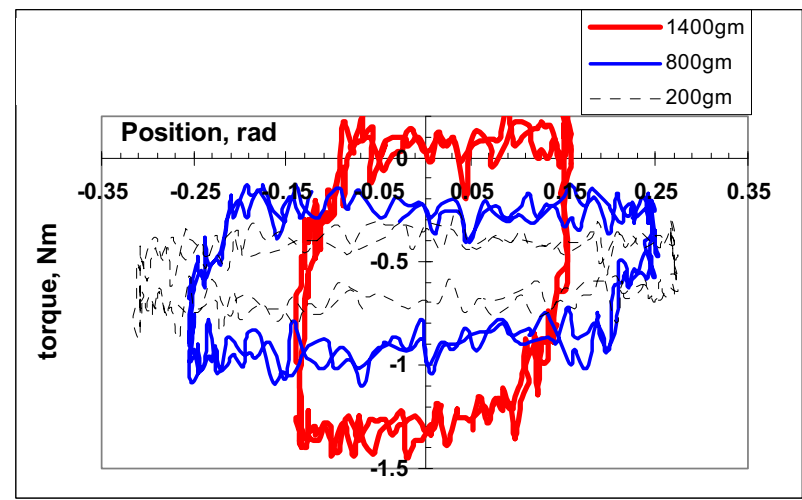

Fig. 9. Work loops at differing brake loads $-\mathrm{f}=0.805 \mathrm{~Hz} \mathrm{gm}$

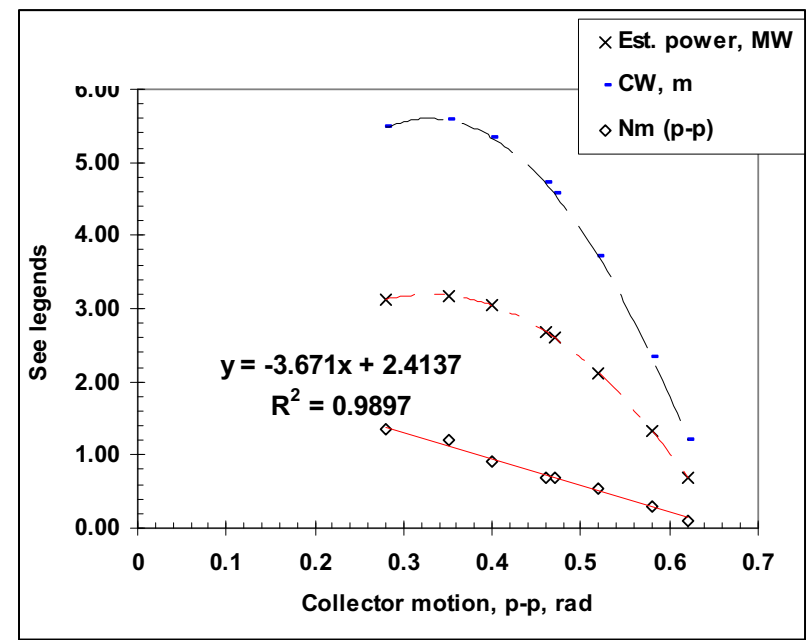

Fig. 10. Power vs collector motio resonant in waves $32 \mathrm{~mm}$ amplitude 


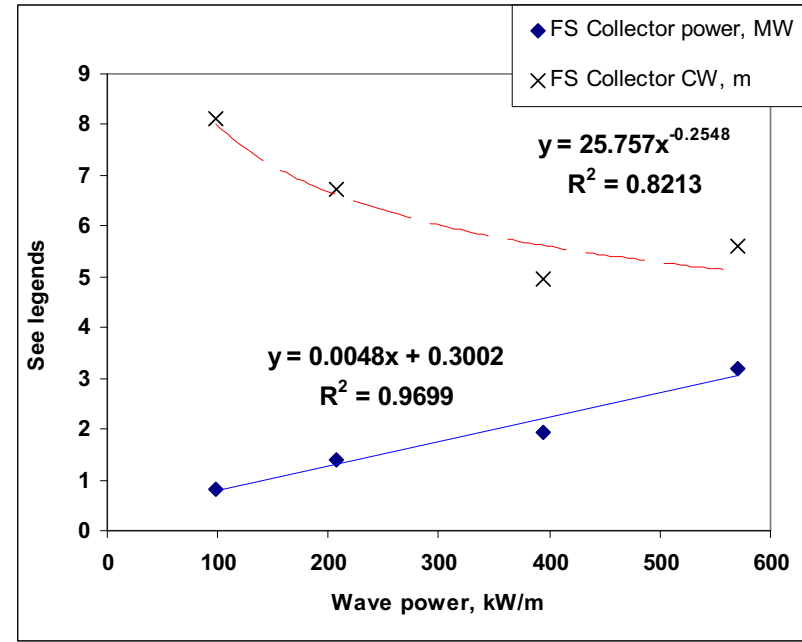

Fig. 11. Collector Power vs wave power

\section{Power in Mixed Seas}

As described above tests were carried out with a fixed, "intermediate" level of brake loading. The brakes exert a dry, or Coulomb, friction load, closely modelling the load that would be applied by a fixed pressure, fixed area hydraulic system at full scale and not the intended, intelligently controlled, system.

Fig. 12 shows a $50 \mathrm{sec}$ wave record at one gauge and fig 13 shows the resulting wave and collector powers. The average scaled-up device power from these results is $1.56 \mathrm{MW}$ from a sea with $830 \mathrm{~kW} / \mathrm{m}$ incident power. This is some $2.75 \mathrm{x}$ lower than device power in regular waves of the same incident power in these experiments.

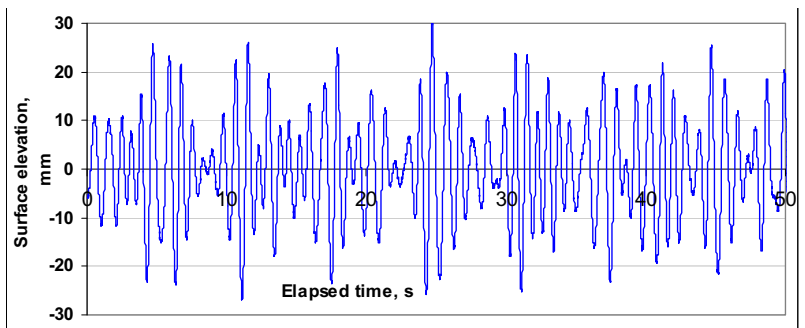

Fig. 12. Mixed waves - Bretshneider $\mathrm{T} p=1.0$ record from gauge 2$57+$ ve zero xings

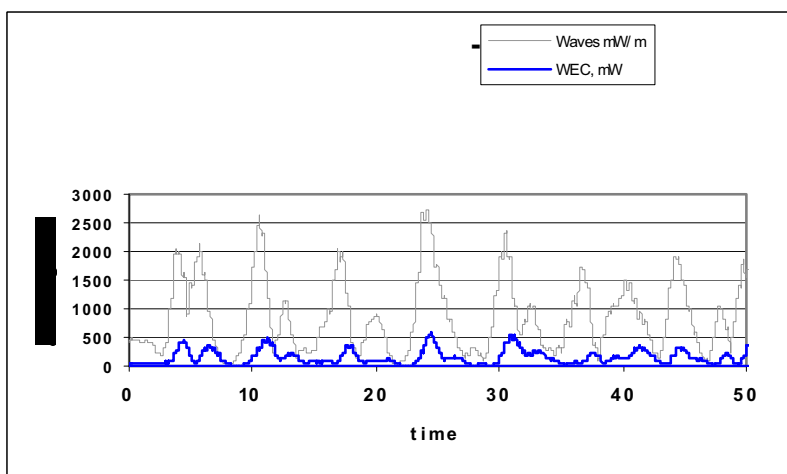

Fig. 13. WRASPA in mixed waves

\section{Forces in Extreme Waves}

Horizontal forces at the pivot due to drag on the collector body and arm are shown in Fig.14. Forces appear quite small and increase with increasing wave amplitude. The arm moves to natural angles determined by wave and buoyancy forces. A few readings were taken from video records and these showed that in large, non-breaking waves the motion amplitudes peaked at $27^{\circ}$ $23^{\circ}$ and $20^{\circ}$ in waves of $0.625,0.91$ and $1 \mathrm{~Hz}$ respectively. In going from non-breaking to breaking waves the collector amplitude decreased noticeably, e.g. from 20 to $14^{0}$ at $1 \mathrm{~Hz}$. In breakers the collector's motion was biased "landwards" and the motion was nonsinusoidal.

Behaviour and forces in extreme conditions will require further study but these results suggest that storm survival will not be a problem and that peak structural forces will be acceptably low.

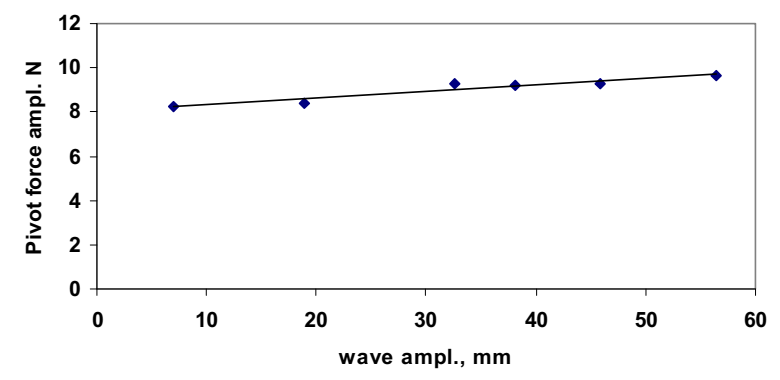

Fig. 14. Pivot force amplitude vs wave amplitude $-\mathrm{f}=0.625 \mathrm{~Hz}$

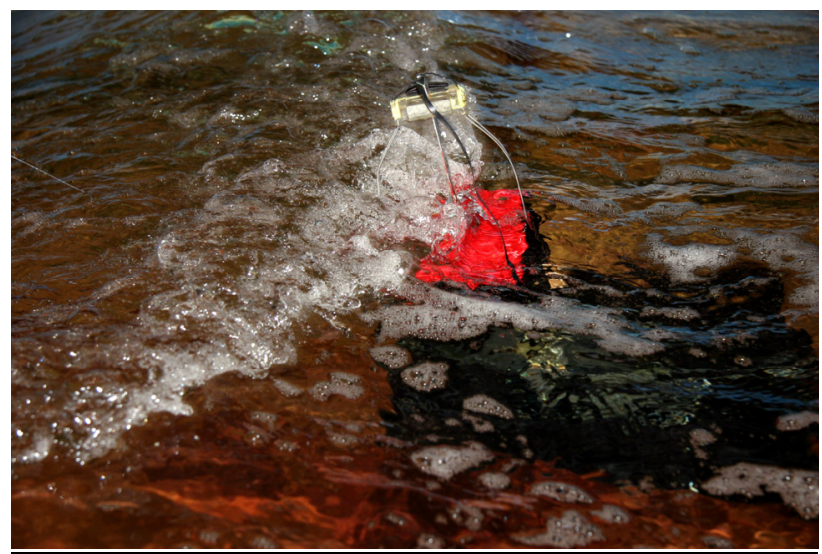

Fig.15 Model subject to breaking wave

\section{CONCLUSIONS}

1. These preliminary tests show that WRASPA is a viable concept.

2. In its present form, at full scale, it could have a capture width of in excess of 8 metres in waves less than $100 \mathrm{kw} / \mathrm{m}$. 
3. In larger waves capture width decreases but wave power will be limited in any case by its installed power handling capacity.

4. Further tests in small waves should be conducted with the collector position and shape altered to give resonance at, or slightly higher than, $1 \mathrm{~Hz}$. (equivalent to $10 \mathrm{sec}$ at full scale)

5. Collectors of different shapes should be tested to increase power e.g. by reducing drag.

6. These initial tests show that further work on control methods is vital as are comprehensive measurements and modelling of such devices in extreme seas in their likely marine situations.

7. The Lancaster wave tank worked well but to model N W Atlantic / Continental Shelf conditions it may be necessary to extend the length of the tank or test at a smaller scale when testing in extreme seas.

8. As device development progresses testing in mixed and directionally spread seas will become important and for this we will approach Edinburgh University.

\section{REFERENCES}

[1] French, M and Bracewell, R, The systematic design of economic wave energy converters 5th International Offshore and Polar Engineering Conference, The Hague, June 11-16, 1995

[2] Carter, R G and Hurdle, D P, Wave energy absorption by a small body moving in surge. Applied Ocean Res, 1983, vol.5, No. 1 pp. 24-29

[3] Evans D V "Some analytic results for $2 D$ and $3 D$ wave energy absorbers" pp. 213-249 in "Power from Sea Waves" Ed. Count, B M, Ac. Press 1980
[4] Folley M "The design of point absorbing wave energy converters", $\mathrm{PhD}$ thesis, Lancaster University, Sept. 1991

[5] Folley, M, Whittaker, T and Osterried, M "The Oscillating Wave Surge Converter" Paper No. 2004-JSC-377, 2004

[6] Chaplin, R and Folley, M Patras, Poster paper,1998

[7] Chaplin, R V and Widden, "Frond testing" Dec 2002 internal lab report

[8] Folley, M, et al., "The effect of water depth on the performance of a small surging wave energy converter", Ocean Engineering, (2006), doi:10.1016/j.oceaneng.2006.05.015

[9] Budal, K and Falnes, J, "A resonant point absorber of ocean-wave power", Nature vol. 256 pp. 478-479, 1975

[10] McCabe, A P, Bradshaw, A, Meadowcroft, JAC and Aggidis, G "Developments in the deisign of the PS Frog Mk 5 wave energy converter". Renewable Energy $31 \mathrm{pp}$ 141-1512006

[11] Evans D V "Max. power absorption under motion constaints" Applied Ocean Research, 3, pp.200-203, 1981

[12] McCabe, A, Chaplin, R V and French, M J "Some Notes on Shapes and Hydrodynamic Parameters" LUED Wave Power Group WPG Note 13 Version 2 Feb 2004

[13] Chaplin, R, "Surging Point-absorber behaviour" - Internal laboratory note. Lancaster 2006

[14] Ridjanovic, M "Drag coefficients of flat plates oscillating normally to their planes". Shiffsteknik Bd. 9 Heft 45, 1962

[15] Whittaker, T, www.raeng.co.uk/policy/reports/pdf/energy_2100/Trevor_ Whittaker.pdf

[16] Aggidis, G, Mingham, C “A Joint Numerical and Experimental Investigation of a Point Absorbing Wave Energy Converter" Proposal to Joule Centre, Manbchester, 2007

[17] Edinburgh Designs www.edesign.co.uk/

[18] Taylor, J M Personal communication. Edinburgh, 2002

[19] World Energy Council www.worldenergy.org/wecgeis/edc/countries/UnitedKingdom.asp

[20] Meadowcroft, J A C, Stallard, T J and Baker, N J "Absorbtion of energy from irregular waves by a surging buoy". Procs. EWTEC 2005

[21] Callaghan, J Ed. "Future Marine Energy" The Carbon Trust Report CTC601 2006 